\title{
Contraception and Venous Thromboembolism: Risk Factors and Clinical Considerations
}

\author{
Ashley Waddington ${ }^{1}$, Carrie Ferguson ${ }^{2}$, Robert L. Reid ${ }^{1}$ \\ ${ }^{1}$ Division of Reproductive Endocrinology, Department of Obstetrics and Gynaecology, Queen's University, Kingston, Canada \\ ${ }^{2}$ Department of Obstetrics and Gynaecology, Memorial University of Newfoundland, St. John’s, Canada \\ Email: *Ashley.Waddington@queensu.ca
}

How to cite this paper: Waddington, A., Ferguson, C. and Reid, R.L. (2017) Contraception and Venous Thromboembolism: Risk Factors and Clinical Considerations. Open Journal of Obstetrics and Gynecology, 7, 16-30

http://dx.doi.org/10.4236/ojog.2017.71003

Received: July 5, 2016

Accepted: December 20, 2016

Published: December 23, 2016

Copyright (C) 2017 by authors and Scientific Research Publishing Inc. This work is licensed under the Creative Commons Attribution International License (CC BY 4.0). http://creativecommons.org/licenses/by/4.0/

\begin{abstract}
Venous thromboembolism (VTE) is a known risk with some forms of hormonal contraception, and should be considered by health care providers when counselling patients about their contraceptive options. Various other risk factors exist for VTE, including family history of VTE and a personal history of VTE or thrombophilia. This article will summarize various known risk factors for VTE, as well as what is known about the VTE risk imparted by the use of different contraceptives.
\end{abstract}

\section{Keywords}

Venous Thromboembolism, Family History, Contraception

\section{Introduction}

An increased risk of venous thromboembolism (VTE) is a known risk with some forms of hormonal contraception and this is an important consideration when health care providers (HCPs) counsel patients about contraceptive options. A patient's medical history may indicate an increased personal risk for VTE; thus HCPs need to know what level of risk the patient's history imparts and the impact of various contraceptive methods on that individual's risk. No single contraceptive method will be a suitable fit for all women so HCPs need to understand the range of available contraceptive options and, with the woman, need to consider the benefits and risks of each.

VTE remains a major cause of morbidity and mortality worldwide. Some estimates suggest that in the USA alone close to 1 million people are affected each year. Of these, deep vein thrombosis (DVT) resulting in pulmonary embolism (PE) kills approximately 60,000 people per year. One quarter of cases of PE present with sudden death and as many as $1 / 3$ of cases die within a month of diagnosis. Among people who survive DVT, one-half will have long-term complications (post-thrombotic syndrome) such as swelling, pain, discoloration, and scaling in the affected limb. These statistics 
reflect all cases of VTE, many of whom are elderly, immobilized or have major comorbidities such as obesity or cancer [1].

Some forms of hormonal contraception are known to be a risk factor for VTE [2]. Because these methods are used by an estimated 100 million women worldwide (10 million in the USA), even though the absolute risk is small, they have the potential to be a significant contributor to overall VTE numbers.

Hormonal contraception is typically used in women ages 12 - 50 and the background rate of VTE in this population varies considerably in published data. In 2007 Heinemann and Dinger published a review of the range of baseline estimates of VTE in this population. They suggested that the variation in quoted risk was partly due to differences in methodology as well as definitions of VTE and the sensitivity of diagnostic tests over time. However they concluded in their analysis that the true incidence in women not using hormonal contraception was approximately 4 - 5 per 10,000 women years [3].

This article will highlight important clinical considerations for HCPs with regard to VTE risk and contraception. It will start with a review of risk factors for VTE, including the inherited thrombophilias, followed by a review of contraceptive options and their expected influence on VTE risk.

\section{Risk Factors for VTE}

Traditional teaching about VTE focused on the triad of endothelial dysfunction, hypercoagulability, and hemodynamic changes such as stasis or turbulence. Labeled "Virchow's triad" in the 1950's, long after Virchow's death in 1902, it recognized his important discovery of the association between DVT and PE in 1856. In recent years our understanding of risk factors for DVT has grown steadily.

Risk factors for VTE may be inherited or acquired, and some are modifiable. Evidence suggests these risks related to hormones may act synergistically and in some cases may actually be super additive [4] [5] [6].

\subsection{Pregnancy}

Pregnancy is a time of significant risk for VTE even in healthy young women [7] [8] [9]. While the absolute risk of a pulmonary embolism during pregnancy or postpartum is low, pulmonary emboli remain one of the leading causes of maternal death in developed countries [10] [11]. Some studies suggest that the days around delivery bear the highest risk [12] [13]. The MEGA (Multiple Environmental and Genetic Assessment of risk factors for venous thrombosis) study found that the risk of venous thrombosis was 5-fold increased during pregnancy (OR, 4.6; 95\% CI, 2.7 - 7.8) and 60-fold increased during the first 3 months after delivery compared with non-pregnant women (OR, 60.1; 95\% CI, 26.5 - 135.9) [14]. Translated into women years, per 10,000 women 29 events would occur in pregnancy and over 300 in the postpartum period [15].

\subsection{Obesity}

Obesity is an independent risk factor for VTE. Lifestyle and socioeconomic factors have been linked to the increasing prevalence of obesity in the North American population. 
Obesity defined as a body mass index (BMI) of greater than $30 \mathrm{~kg} / \mathrm{m}^{2}$, is associated with an increased risk of thrombosis [16] [17]. Tsai et al. found that the hazard ratios for BMIs greater than 30, 35, and 40 after controlling for age, sex, and race were 2.23 (95\% CI 1.5 - 3.11), 1.52 ((5\% CI, 0.78 - 2.96), and 2.71 (95\% CI, 1.26 - 5.84), respectively. Similar results were obtained in the Copenhagen City Heart Study with a hazard ratio for VTE in individuals with BMI > 30 (compared to BMI < 20) being 2.10 (95\% CI, 1.39 - 3.16). In the case-control PILI Genetic Risk monitoring (PILGRIM) Study, Suchon et al. found an Odds ratio of 3.46 (95\% CI, 1.81 - 7.03) for patients with a BMI over 35 [18].

\subsection{Polycystic Ovary Syndrome}

Women with polycystic ovary syndrome (PCOS) may have the added burden of a genetic risk for weight gain, and may also have an increased risk of VTE above what would be expected based on BMI alone. Women with PCOS, many of whom are prescribed hormonal contraceptives for the non-contraceptive benefits of menstrual regulation and suppression of hyperandrogenism [19], have increased baseline risk for VTE. Among women aged 18 - 24 with PCOS the adjusted odds ratio for VTE was 3.26 (95\% CI, 2.61 - 4.08) [20]. In another population-based cohort study examining VTE risk among women with PCOS who were not using hormonal contraception the relative risk of VTE compared to non PCOS subjects was 1.55 (95\% CI 1.10 - 2.19) [21]. This risk of VTE in women with PCOS may be further augmented by exposure to hormonal contraceptives [4] [21] [22].

\subsection{Trauma, Surgery and Immobility}

Trauma [23], surgery [24] and immobility [25] all elevate the risk for VTE although the extent of risk depends on the numerous factors such as type and length of surgery [26], use of anticoagulation [27] [28], degree or duration of immobility, etc.

\subsection{Malignancy}

Malignancy also poses a risk for development of VTE and although most patients will have a known cancer diagnosis prior to a thrombotic event, occasionally this diagnosis is made thereafter [29] [30] [31].

\subsection{Chronic Medical Conditions and Smoking}

Chronic medical diseases and smoking may be linked to an increased risk for VTE but the evidence, to date, is conflicting. One meta-analysis of cardiovascular risk factors found the risk of VTE was 2.33 for obesity ( $95 \%$ CI, 1.68 to 3.24), 1.51 for hypertension (95\% CI, 1.23 to 1.85), 1.42 for diabetes mellitus (95\% CI, 1.12 to 1.77 ), 1.18 for smoking ( $95 \% \mathrm{CI}, 0.95$ to 1.46 ), and 1.16 for hypercholesterolemia ( $95 \% \mathrm{CI}, 0.67$ to 2.02 ) [32]. While smoking was not statistically significant in this analysis, other individual studies have suggested an increased risk. The MEGA case control study demonstrated an Odds Ratio for VTE in current smokers of 1.43 (95\% CI, 1.28 - 1.60), while former smokers had an Odds Ratio of 1.23 (95\% CI, 1.09-1.38). Heavy smokers with a $\geq 20$ pack-year history had an Odds Ratio of 4.30 (95\% CI, 2.59 - 7.14), and women who 
smoked while using combined hormonal oral contraceptives had an Odds Ratio of 8.79 (95\% CI, 5.73 - 13.49) [33]. In the case-control PILI Genetic Risk monitoring (PILGRIM) Study, Suchon et al. found an Odds Ratio for smokers of 1.65 (95\% CI, 1.30 - 2.10) [18].

\subsection{Air Travel}

Air travel has also been identified as an important contributor to VTE, likely due to a combination of cramped seating, immobility, hypoxia and dehydration [34]. In the MEGA study [35] Cannegieter et al. found an overall Odds Ratio of 2.1 (95\% CI 1.5 3.0), and they estimated that the odds ratio for women using combined oral contraceptives could be as high as 20-fold. In a case control study, Martinelli et al. also found the overall Odds Ratio to be 2.1 (95\% CI, 1.1 - 4.0), and for women using combined hormonal oral contraceptives the Odds ratio was 13.9 (95\% CI 1.7 - 117.5) [36].

\subsection{Age}

Advancing age is an important contributor to VTE risk. During the reproductive years the background rate of VTE is low but steadily increasing [37] [38] [39]. Occasionally combined hormonal contraception is used in older women during the perimenopausal transition to regulate bleeding and reduce intermittent menopausal symptoms. A Dutch case-control study examined the impact of hormonal contraception on VTE in women beyond age 50. The relative risk of venous thrombosis was especially high in women using oral contraception with one or more thrombophilic defects, with an OR of 16.3 (95\% CI, 9.2 - 28.9). When the same analysis was performed using family history as a proxy for genetic thrombophilia the results were very similar OR 14.2 (95\% CI, 6.7 - 30.0) for oral contraception use [40].

\subsection{Blood Type}

For patients with non-O blood type (compared to O blood type), the risk of VTE is elevated. A cohort study by Sode et al. determined that the hazard ratio for VTE is 1.4 (95\% CI, 1.3 - 1.5) and there is an even greater impact when combined with Factor V Leiden and Prothrombin gene mutations [41]. In the case-control PILI Genetic Risk monitoring (PILGRIM) Study, Suchon et al. found an Odds ratio of 1.98 (95\% CI, 1.57 - 2.49) for non-O blood type [18]. In post-menopausal women, non-O blood type is associated with a variety of pro-coagulant changes in coagulation factors when hormone replacement treatment is used [42].

\subsection{Family History}

Family history of VTE is an independent risk factor for VTE [6]. When the family history indicates a member with a known VTE the Odds Ratio for a thrombophilia is increased 2-fold (OR 2.2, 95\% CI, 1.9 - 2.6) and up to 4-fold (OR 3.9, 95\% CI, 2.7 - 5.7) when more than one family member has been affected [43]. Accordingly it is important to confirm whether the affected relative was screened for a thrombophilia and if so, the result of that screening. If an underlying hereditary thrombophilia is present in a first degree relative, or when one or more relatives have a documented VTE (especially under age 50) screening for thrombophilia is generally warranted prior to the initiation of 
hormonal contraception [6]. Universal screening for thrombophilias for all contraception users is not feasible due to excessive cost [44] [45] however, selective screening for thrombophilias in patients with a family history of VTE may be warranted.

\section{Inherited Thrombophilias}

Inherited thrombophilias are estimated to affect $5 \%$ to $8 \%$ of the U.S. population. The level of risk varies according to the type of thrombophilia. Coagulation always necessitates a balance between pro-coagulant and anti-coagulant factors resulting in two ways that a thrombophilia can induce hypercoagulability: a deficiency in anti-thrombotic regulating factors or a gain of function for a pro-coagulant factor.

The inherited thrombophilias include genetic defects in both of these categories, leading to variable degrees of hypercoagulability [43] [46] [47]. Gain of function mutations are more common than deficiency mutations.

\subsection{Gain of Function Mutations}

Mutations in the Prothrombin (G20210A) gene, or the Factor V Leiden gene lead to hypercoagulability by increasing pro-coagulant factors.

\subsubsection{Mutations in the Prothrombin (G20210A) Gene}

Prothrombin (G20210A) mutation is present in $0.7 \%$ - 4\% of the European population, with geographic variation noted [48]. In affected individuals, prothrombin levels can be $30 \%$ higher than in unaffected individuals and this leads to increased coagulability. The relative risk of VTE compared to unaffected individuals is 2.8 (95\% CI, 1.4 - 5.6) [49].

\subsubsection{Factor $V$ Leiden}

Mutation of the Factor V Leiden (FVL) gene affects $1 \%-8.5 \%$ of the Caucasian population, and is the most common thrombophilia in this population [50] [51]. Also referred to as "Activated Protein C resistance", Factor V Leiden leads to a mutation in Factor V that prevents it from being inactivated by the powerful anti-coagulant factor called Protein C. Heterozygous carriers of the Factor V Leiden mutation have an approximately 7-fold increased risk of VTE compared to unaffected individuals. In a casecontrol study, Price et al. calculated an Odds ratio of 6.6 (95\% CI, 3.6 - 12.0) [52], and homozygous carriers (who account for only $1 \%$ of FVL carriers) are estimated to have as much as an 80-fold increased risk of VTE [53].

Interestingly, the increased risk of VTE in women who are FVL carriers and who use combined hormonal contraception may be increased to a greater degree than would be estimated based on the relative risks of either risk factor alone. In this context, the relative risk of VTE conferred by these two risk factors may be multiplicative rather than additional. In a case-control study, Vandenbroucke et al. found an Odds Ratio of 34.7 ( $95 \%$ CI, 7.8 - 154) for women with both risk factors, compared to women with neither risk factor [46].

\subsection{Deficiency of Function Mutations}

Protein C deficiency, Protein S deficiency and Antithrombin deficiency are rare yet important inherited thrombophilias because they increase the risk of clotting signifi- 
cantly in affected individuals. These thrombophilias result from a deficiency in anticoagulant factors in the clotting cascade.

\subsubsection{Protein C Deficiency}

Heterozygosity for protein $\mathrm{C}$ deficiency is inherited in an autosomal dominant fashion and affects between $0.2 \%-0.5 \%$ of the population [54] [55]. However, there is a lot of variation in phenotype and many carriers will be asymptomatic. A retrospective cohort family study determined that the relative risk of thrombosis in carriers of protein $\mathrm{C}$ deficiency is 7.3 (95\% CI, 2.9 - 18.4) [56], while a case-control study [57] suggests a relative risk of 6.5 (95\% CI, 1.8 - 24). A meta-analysis of observational studies [58] demonstrated an odds ratio of thrombosis of 7.51 (95\% CI, 3.21 - 17.52). It should be noted that Protein $\mathrm{C}$ deficiency can also be acquired, most often in the setting of severe infection or sepsis.

\subsubsection{Protein S Deficiency}

Protein $\mathrm{S}$ is a cofactor of Protein $\mathrm{C}$ and confers an anticoagulant effect on the clotting cascade. Mutations in the gene coding for protein $\mathrm{S}$ are inherited in an autosomal dominant fashion. The prevalence of protein $S$ deficiency is between $0.03 \%-0.13 \%$ [59]. A retrospective cohort family study determined that the relative risk of thrombosis in carriers of protein S deficiency is 8.5 (95\% CI, 3.5 - 20.8) [56], while a meta-analysis of observational studies [58] found a slightly lower odds ratio for thrombosis of 5.37 (95\% CI, 2.70 - 10.67). Protein S deficiency can also exist in an acquired form, and may be present in conditions such as pregnancy, oral contraceptive use, disseminated intravascular coagulation (DIC), nephrotic syndrome and liver disease.

\subsubsection{Antithrombin Deficiency}

Antithrombin (also referred to as Antithrombin III) is a naturally occurring enzyme inhibitor with anticoagulant properties. As its name suggests, it inhibits thrombin, but it also has effects on Factor Xa and Factor IXa in the coagulation cascade.

Hereditary deficiency of antithrombin has a prevalence of approximately $0.02 \%$ $0.2 \%$ [60]. A retrospective cohort family study determined that the relative risk of thrombosis in carriers of antithrombin deficiency is 8.1 (95\% CI, 3.4 - 19.6) [56], while a meta-analysis of observational studies [58] found a higher odds ratio for thrombosis of 16.26 (95\% CI, $9.90-26.70)$.

\section{Contraceptive Options and VTE Risk}

When counselling patients about contraceptive options, VTE risk is only one of several considerations. Individualized counselling is needed, to ensure that risks, benefits and patient preferences are all considered.

An important consideration in choosing a contraceptive method is the effectiveness of the method in preventing pregnancy. While barrier methods and natural family planning methods carry no risk for VTE, they also have much higher failure rates than hormonal methods [61]. When considering VTE risk, it must be recalled that pregnancy confers a higher risk of VTE compared to the use any hormonal contraceptive method, and thus the risk of pregnancy must factor in to method selection. In an article 
by van Vlijmen et al. [62], mathematical modeling was used to estimate the VTE risk for women with factor V Leiden mutations using combined oral contraceptives, intrauterine contraceptives and male condoms, taking into account the VTE risk associated with the contraceptive method itself, as well as VTE risk due to unintended pregnancies related to contraceptive failure. In their analysis, it was estimated that women with Factor V Leiden mutations who used condoms for contraception have an increased risk of VTE compared to those who used COCs, due to the higher risk of contraceptive failure and consequent pregnancy-related VTE. The authors advocate for a rational approach to contraceptive counselling and encourage HCPs not to unnecessarily deny patients access to effective contraception when the potential for pregnancy is higher in contraceptive non-users or users of less effective methods.

Long-acting reversible contraceptives (LARCs) are the most efficacious and include intrauterine devices and contraceptive implants. The copper IUD and levonorgestrel Intrauterine System (LNG-IUS) provide $99.2 \%$ and $99.8 \%$ efficacy at pregnancy prevention, respectively [61] and are not associated with an increased risk of VTE [63] [64]. The progestin secreting contraceptive implant has a $99.95 \%$ efficacy at preventing pregnancy and also does not increase the risk of VTE [65].

\subsection{Copper Intrauterine Devices (IUDs)}

Copper IUDs do not increase the risk of VTE and are very effective at preventing pregnancy. This may be a safe choice for women with VTE risk factors. It should be noted that copper IUDs may increase the risk of menorrhagia and/or dysmenorrhea for some women [66], and therefore their use may not be acceptable to women using anticoagulation (for example, women with a personal history of VTE and/or a high risk thrombophilia).

\subsection{Combined Hormonal Contraceptives}

Combined hormonal contraceptives (CHCs), whether pill, patch, or vaginal ring, are known risk factors for VTE [15] [67] [68]. With the introduction of the sub-50 $\mu$ g estrogen combined oral contraceptives there was a fall in VTE risk compared to older higher dose formulations and because of this the risk of VTE has been largely attributed to the procoagulant effects of estrogen. While lowering of the estrogen dose in newer pills to $10-20 \mu \mathrm{g}$ per tablet may further reduce the risk of VTE [39] [69] there is, to date, no compelling evidence to support this premise. Contemporary combined hormonal contraceptives are estimated to double the background risk of VTE from 4 5/10,000 to approximately $9-10 / 10,000$ women years [3] [70].

In recent years an apparent increase in VTE risk associated with the progestin component of combined hormonal contraception has ignited a debate about the validity of the research and the potential for confounding by indication. Third generation progestins have been preferentially prescribed to women with higher baseline risk for VTE because they were thought to confer less metabolic risk. Similarly other progestins with strong anti-androgenic effects (cyproterone acetate and drospirenone) have been preferentially prescribed to women with obesity and androgenic features of PCOS [22] [70] [72]. 
Several database studies suggest greater VTE risk with combined hormonal contraceptive products containing third generation progestins (desogestrel and gestodene) and those containing drospirenone than with second generation products containing levonorgestrel. Comparing levonorgestrel to other progestins Lidegaard reported a Relative Risk for desogestrel of 2.2 (95\% CI, 1.7 - 3.0), gestodene of 2.1 (95\% CI, 1.6 2.8), drospirenone 2.1 (95\% CI, 1.6 - 2.8) [39]. These studies have been criticized for significant methodological deficiencies [15] [71] [72]. Several higher quality prospective cohort studies have shown no differences in VTE risk between products based on progestin formulation [70] [73] [74] [75] [76]. The International Active Surveillance Study of Women Taking Oral Contraceptives (INAS) study reported a RR of 0.8 (95\% CI, 0.4 - 1.5) when comparing VTE rates with drospirenone vs levonorgestrel [75].

The risk of VTE in women on combined hormonal contraception is greatest in the first months of use [70] [76] and may relate to the uncovering of an, as yet, undiagnosed thrombophilia [77]. Discontinuation of combined hormonal contraception returns the risk of VTE to baseline after the first month [78].

\subsection{Progestin-Only Contraceptives}

Progestin-only contraceptives (levonorgestrel Intrauterine Systems (LNG-IUS), implants, injectables, and pills) have generally not shown an increased risk of VTE in users [64] [79]. Two meta-analyses that included studies of all forms of progestin-only contraception have been undertaken, and both show reassuring results. In a metaanalysis by Mantha et al. [64], the adjusted Relative Risk for VTE for users vs. nonusers of progestin-only contraceptives was 1.03 (95\% CI, 0.76 - 1.39). A Meta-analysis by Bergendal et al. [79] demonstrated an overall Odds Ratio of 1.45 which was not statistically significant (95\% CI, 0.92 - 2.26).

Controversy exists over whether or not there is a possible increased risk of VTE with Depomedroxyprogesterone acetate (DMPA) injections. The WHO Collaborative Study of Cardiovascular Disease and Steroid Hormone Contraception [80], a case-control study, demonstrated a statistically insignificant increased risk of VTE in users of DMPA, with an adjusted Odds Ratio of 2.19 (95\% CI 0.66 -7.26), while another casecontrol study by van Hylckama Vlieg et al. [63] demonstrated an adjusted Odds Ratio of 3.0 (95\% CI, 1.2 - 7.5), adjusted for BMI, family history of VTE and smoking status. A meta-analysis assessing the risk of venous thromboembolic events in women taking progestin-only contraception included a sub group analysis of DMPA users that included both the WHO and van Hylckama Vlieg studies which revealed an increased relative risk of 2.67 (95\% CI 1.29 to 5.53). The authors concluded that further research was necessary as there were only the two studies included within this subgroup [64]. It should be noted that in these case-control studies there may be residual confounding based on potential for prescription bias (patients with a perceived higher risk of VTE could have been preferentially prescribed DMPA) or indication bias (patients may have been using DMPA for indications other than solely contraception).

Progestin-only pills (POPs) do not increase the risk of VTE. The WHO Collaborative Study of Cardiovascular Disease and Steroid Hormone Contraception [80], a casecontrol study, demonstrated a non-significant increase in VTE risk with POP use, with 
an adjusted Odds Ratio of 1.82 (95\% CI, 0.79 - 4.22). The Transnational Study on Oral Contraceptives and the Health of Young Women [81], a case-control study, demonstrated an adjusted Odds Ratio of 0.68 (95\% CI, 0.28 - 1.66) for VTE in POP users compared to non-oral contraceptive users. A cohort study by Lidegaard et al. [39] demonstrated an adjusted Relative Risk of VTE for users of Norethisterone POPs of 0.56 (95\% CI, 0.29 - 1.07) and an adjusted RR for users of Desogestrel POPs of 0.64 (95\% CI 0.29 - 1.42). The relative risk for the subgroup of POP users in the metaanalysis by Mantha et al. [64] was 0.90 (95\% CI, 0.57 - 1.45).

Progestin-only implants do not appear to increase the risk of VTE, although there are few published studies on this topic. The follow-up analysis by Lidegaard et al. [65] of the registry-based Danish cohort study on non-oral hormonal contraception included an analysis of users of the subcutaneous etonogetrel implant (Implanon ${ }^{\circledR}$ ). The adjusted Relative Risk of VTE (compared to non-users of contraception) was non-significant at 1.40 (95\% CI, 0.58 - 3.38).

The Levonorgestrel secreting intrauterine systems (LNG-IUS) do not increase the risk of VTE. A retrospective cohort based study by Lidegaard et al. [65] on non-oral hormonal contraception demonstrated an adjusted Relative Risk of 0.57 (95\% CI, 0.41 0.81 ), which suggests a protective effect although a physiological explanation for this is not elucidated. In a case-control study, van Hylckama Vlieg [63] also demonstrated a low risk of VTE in users of LNG-IUS, with an adjusted Odds Ratio of 0.3 (95\% CI, 0.1 1.3), which also suggests a protective effect but does not reach statistical significance. In a meta-analysis that included both the Lidegaard and Vlieg studies, Mantha et al. calculated relative risk of 0.61 (95\% CI, $0.24-1.53)$ [64].

\section{Conclusion}

Risk factors for VTE should be elicited prior to prescribing hormonal contraception. A positive family history of VTE may be, and positive family history for a thrombophilia should be, an indication for thrombophilia screening prior to prescribing hormonal options. An individualized risk/benefit discussion and knowledge of a range of contraceptive options should minimize the risk of VTE while affording effective contraception. Non hormonal and progestin-only methods appear to offer the greatest margin of safety.

\section{References}

[1] Wakefield, T.W., McLafferty, R.B., Lohr, J.M., Caprini, J.A., Gillespie, D.L. and Passman, M.A., on Behalf of the Executive Committee of the American Venous Forum (2009) Call to Action to Prevent Venous Thromboembolism. Journal of Vascular Surgery, 49, 1620-1623. https:/doi.org/10.1016/j.jvs.2009.01.058

[2] Heit, J.A. (2005) Venous Thromboembolism: Disease Burden, Outcomes and Risk Factors. Journal of Thrombosis and Haemostasis, 3, 1611-1617. https:/doi.org/10.1111/j.1538-7836.2005.01415.x

[3] Heinemann, L.A.J. and Dinger, J.C. (2007) Range of Published Estimates of Venous Thromboembolism Incidence in Young Women. Contraception, 75, 328-336. https:/doi.org/10.1016/j.contraception.2006.12.018

[4] Seaman, H.E., de Vries, C.S. and Farmer, R.D.T. (2004) Venous Thromboembolism Asso- 
ciated with Cyproterone Acetate in Combination with Ethinyloestradiol (Dianette): Observational Studies Using the UK General Practice Research Database. Pharmacoepidemiology and Drug Safety, 13, 427-436. https:/doi.org/10.1002/pds.896

[5] Eisenberger, A. and Westhoff, C. (2014) Hormone Replacement Therapy and Venous Thromboembolism. Journal of Steroid Biochemistry and Molecular Biology, 142, 76-82. https:/doi.org/10.1016/j.jsbmb.2013.08.016

[6] Rabe, T., Luxembourg, B., Ludwig, M., Dinger, J.C., Bauersachs, R., Rott, H., Mueck, A.O. and Albring, C. (2011) Contraception and Thrombophilia-A Statement from the German Society of Gynecological Endocrinology and Reproductive Medicine and the Professional Association of the German Gynaecologists. Journal of Reproductive Medicine and Endocrinology, 8, 178-218.

[7] James, A.H., Jamison, M.G., Brancazio, L.R. and Myers, E.R. (2006) Venous Thromboembolism during Pregnancy and the Postpartum Period: Incidence, Risk Factors, and Mortality. AJOG, 194, 1311-1315. https:/doi.org/10.1016/j.ajog.2005.11.008

[8] Wu, P., Poole, T.C., Pickett, J.A., Bhat, A. and Lees, C.C. (2013) Current Obstetric Guidelines on Thromboprophyaxis in the United Kingdom: Evidence Based Medicine? European Journal of Obstetrics \& Gynecology and Reproductive Biology, 168, 7-11. https:/doi.org/10.1016/j.ejogrb.2012.12.022

[9] Abbasi, N., Balayla, J., Laporta, D.P., Kezouh, A. and Abenhaim, H.A. (2014) Trends, Risk Factors and Mortality among Women with Venous Thromboembolism during Labour and Delivery: A Population-Based Study of 8 Million Births. Archives of Gynecology and Obstetrics, 289, 275-284. https:/doi.org/10.1007/s00404-013-2923-8

[10] Say, L., Gemmill, A., Tuncalp, Ö., et al. (2014) Global Causes of Maternal Death: A WHO Systematic Analysis. Lancet Global Health, 2, e323-e333. https:/doi.org/10.1016/s2214-109x(14)70227-x

[11] Clark, S.L. (2012) Strategies for Reducing Maternal Mortality. Seminars in Perinatology, 36, 42-47. https:/doi.org/10.1053/j.semperi.2011.09.009

[12] Heit, J., Kobbervig, C. and James, A. (2005) Trends in the Incidence of Venous Thromboembolism during Pregnancy or Postpartum: A 30-Year Population-Based Study. Annals of Internal Medicine, 143, 697-706. https:/doi.org/10.7326/0003-4819-143-10-200511150-00006

[13] Salonen Ros, H., Lichtenstein, P., Bellocco, R., Petersson, G. and Cnattingius, S. (2001) Increased Risks of Circulatory Diseases in Late Pregnancy and Puerperium. Epidemiology, 12, 456-460. https:/doi.org/10.1097/00001648-200107000-00016

[14] Pomp, E., Lenselink, A., Rosendaal, F. and Doggen, C. (2008) Pregnancy, the Postpartum Period and Prothrombotic Defects: Risk of Venous Thrombosis in the MEGA Study. Journal of Thrombosis and Haemostasis, 6, 632-637. https:/doi.org/10.1111/j.1538-7836.2008.02921.x

[15] Reid, R.L., Westhoff, C., Mansour, D., de Vries, C., Verhaeghe, J., Boschitsch, E., Gompel, A., Birkhäuser, M., Krepelka, P., Dulicek, P., Iversen, O.-E., Khamoshina, M., Vrabic Dezman, L., Fruzzetti, F., Szarewski, A., Wilken-Jensen, C., Seidman, D., Kaaja, R. and Shapiro, S. (2010) Oral Contraceptives and Venous Thromboembolism Consensus Opinion from an International Workshop held in Berlin, Germany in December 2009. Journal of Family Planning and Reproductive Health Care, 36, 117-122.

https:/doi.org/10.1783/147118910791749425

[16] Tsai, A., Cushman, M., Rosamond, W., Heckbert, S., Polak, J. and Folsom, A. (2002) Cardiovascular Risk Factors and Venous Thromboembolism Incidence: The Longitudinal Investigation of Thromboembolism Etiology. Archives of Internal Medicine, 162, 1182-1189. https:/doi.org/10.1001/archinte.162.10.1182

[17] Hoist, A., Jensen, G. and Prescott, E. (2010) Risk Factors for Venous Thromboemobolism: 
Results from the Copenhagen City Heart Study. Circulation, 121, 1896-1903. https:/doi.org/10.1161/CIRCULATIONAHA.109.921460

[18] Suchon, P., Al Frouh, F., Henneuse, A., et al. (2015) Risk Factors for Venous Thromboembolism in Women under Combined Oral Contraceptive. The PILI Genetic Risk Monitoring (PILGRIM) Study. Thrombosis and Haemostasis, 115, 135-142. https:/doi.org/10.1160/TH15-01-0045

[19] ACOG Clinical (2010) Practice Guideline No. 110: Non-Contraceptive Uses of Hormonal Contraceptives. Obstetrics \& Gynecology, 115, 206-218. https:/doi.org/10.1097/AOG.0b013e3181cb50b5

[20] Okoroh, E., Hooper, W., Atrash, H., Yusuf, H. and Boulet, S. (2012) Is Polycystic Ovary Syndrome another Risk Factor for Venous Thromboembolism? United States, 2003-2008. American Journal of Obstetrics and Gynecology, 207, 377.e1-377.e8. https:/doi.org/10.1016/j.ajog.2012.08.007

[21] Bird, S.T., Hartzema, A.G., Brophy, J.M., Etminan, M. and Delaney, J.A. (2013) Risk of Venous Thromboembolism in Women with Polycystic Ovarian Syndrome: A Population-Based Matched Cohort Analysis. CMAJ, 185, E115-E120. https:/doi.org/10.1503/cmaj.120677

[22] Seaman, H.E., de Vries, C.S. and Farmer, R.D.T. (2003) The Risk of Venous Thromboembolism in Women Prescribed Cyproterone Acetate in Combination with Ethinyl Estradiol: A Nested Cohort Analysis and Case Control Study. Human Reproduction, 18, 522-526. https:/doi.org/10.1093/humrep/deg120

[23] McLaughlin, D., Wade, C., Champion, H., Salinas, J. and Holcomb, J. (2009) Thromboembolic Complications Following Trauma. Transfusion, 49, 256S-263S. https:/doi.org/10.1111/j.1537-2995.2008.01989.x

[24] White, R., Zhou, H. and Romano, P. (2003) Incidence of Symptomatic Venous Thromboembolism after Different Elective or Urgent Surgical Procedures. Thrombosis and Haemostasis, 90, 446-455.

[25] Yamada, N., Hanzawa, K., Ota, S., et al. (2015) Occurrence of Deep Vein Thrombosis among Hospitalized Non-Surgical Japanese Patients. Annals of Vascular Diseases, 8, 203209. https:/doi.org/10.3400/avd.oa.14-00132

[26] Jaffer, A., Barsoum, W., Krebs, V., Hurbanek, J., Morra, N. and Brotman, D. (2005) Duration of Anesthesia and Venous Thromboembolism after Hip and Knee Arthroplasty. Mayo Clinic Proceedings, 80, 732-738. https:/doi.org/10.1016/S0025-6196(11)61526-7

[27] Geerts, W., Jay, R. and Code, K. (1996) A Comparison of Low-Dose Heparin with lowMolecular-Weight Heparin as Prophylaxis against Venous Thromboembolism after Major Trauma. New England Journal of Medicine, 335, 701-707. https:/doi.org/10.1056/NEJM199609053351003

[28] Geerts, W., Pineo, G., Heit, J., et al. (2004) Prevention of Venous Thromboembolism: The Seventh ACCP Conference on Antithrombotic and Thrombolytic Therapy. Chest, 126, 338S-400S. https:/doi.org/10.1378/chest.126.3_suppl.338S

[29] Elting, L., Escalante, C. and Cooksley, C. (2004) Outcomes and Cost of Deep Venous Thrombosis among Patients with Cancer. Archives of Internal Medicine, 164, 1653-1661. https:/doi.org/10.1001/archinte.164.15.1653

[30] Blom, J.W., Doggen, C.J., Osanto, S. and Rosendaal, F.R. (2005) Malignancies, Prothrombotic Mutations, and the Risk of Venous Thrombosis. JAMA, 293, 715-722. https:/doi.org/10.1001/jama.293.6.715

[31] Prandoni, P., Lensing, A.W., Büller, H.R., et al. (1992) Deep-Vein Thrombosis and the Incidence of Subsequent Symptomatic Cancer. New England Journal of Medicine, 327, 1128-1133. https:/doi.org/10.1056/NEJM199210153271604 
[32] Ageno, W., Becattini, C., Brighton, T., Selby, R. and Kamphuisen, P. (2008) Cardiovascular Risk Factors and Venous Thromboembolism: A Meta-Analysis. Circulation, 117, 93-102. https:/doi.org/10.1161/CIRCULATIONAHA.107.709204

[33] Pomp, E., Rosendaal, F. and Doggen, C. (2008) Smoking Increases the Risk of Venous Thrombosis and Acts Synergistically with Oral Contraceptive Use. American Journal of Hematology, 83, 97-102. https:/doi.org/10.1002/ajh.21059

[34] Gavish, I. and Brenner, B. (2011) Air Travel and Risk of Thromboembolism. Internal and Emergency Medicine, 6, 113-116. https:/doi.org/10.1007/s11739-010-0474-6

[35] Cannegieter, S.C., Doggen, C.J.M., van Houwelingen, H.C. and Rosendaal, F.R. (2006) Travel-Related Venous Thrombosis: Results from a Large Population-Based Case Control Study (MEGA Study). PLoS Medicine, 3, e307. https:/doi.org/10.1371/journal.pmed.0030307

[36] Martinelli, I., Taioli, E., Battaglioli, T., Podda, G.M., Passamonti, S.M., Pedotti, P. and Mannucci, P.M. (2003) Risk of Venous Thromboembolism after Air Travel: Interaction with Thrombophilia and Oral Contraceptives Archives of Internal Medicine, 163, 27712774. https:/doi.org/10.1001/archinte.163.22.2771

[37] Silverstein, M.D., Heit, J.A., Mohr, D.N., Petterson, T.M., O’Fallon, W.M. and Melton, L.J. (1998) Trends in the Incidence of Deep Vein Thrombosis and Pulmonary Embolism:A Twenty-Five Year Population Based Study. Archives of Internal Medicine, 158, 585-593. https:/doi.org/10.1001/archinte.158.6.585

[38] Oger, E. (2000) Incidence of Venous Thromboembolism: A Community-Based Study in Western France. EPI-GETBP Study Group. Groupe d'Etude de la Thrombose de Bretagne Occidentale. Thrombosis and Haemostasis, 83, 657-660.

[39] Lidegaard, Ø., Nielsen, L.H., Skovlund, C.W., Skjeldestad, F.E. and Løkkegaard, E. (2011) Risk of Venous Thromboembolism from Use of Oral Contraceptives Containing Different Progestogens and Oestrogen Doses: Danish Cohort Study, 2001-9. BMJ, 343, d6423. https:/doi.org/10.1136/bmj.d6423

[40] Roach, R.E.J., Lijfering, W.M., Helmerhorst, F.M., Cannegieter, S.C., Rosendaal, F.R. and Van Hylckama Vlieg, A. (2012) The Risk of Venous Thrombosis in Women over 50 Years Old Using Oral Contraception or Postmenopausal Hormone Therapy. Journal of Thrombosis and Haemostasis, 11, 124-131. https:/doi.org/10.1111/jth.12060

[41] Sode, B.F., Allin, K.H., Dahl, M., Gyntelberg, F. and Nordestgaard, B.G. (2013) Risk of Venous Thromboembolism and Myocardial Infarction Associated with Factor V Leiden and Prothrombin Mutations and Blood Type. CMAJ, 185, E229-E237.

[42] Guimaraes, D.A., dos Santos, M.S., Gomes, K.B., van der Bom, J.G., Rios, D.R., Cardoso, J., Franco, R.M., Teixeira, G.S., Dusse, L.M., Carvalho, M. and Fernandes, A.P. (2012) Interaction between Oral Estrogen plus Progestogen Therapy and ABO Blood Groups on Coagulation Activation in Postmenopausal Women. Menopause, 19, 339-345.

https:/doi.org/10.1097/gme.0b013e31822b721f

[43] Bezemer, I.D., van der Meer, F.J., Eikenboom, J., Rosendaal, F.R. and Doggen, C.J. (2009) The Value of Family History as a Risk Indicator for Venous Thrombosis. Archives of Internal Medicine, 169, 610-615. https:/doi.org/10.1001/archinternmed.2008.589

[44] Vandenbroucke, J.P., van der Meer, F.J., Eikenboom, J. and Rosendaal, F.R. (1996) Factor V Leiden: Should We Screen Oral Contraceptive Users and Pregnant Women? BMJ, 313, 1127-1130. https:/doi.org/10.1136/bmj.313.7065.1127

[45] Wu, O., Robertson, L., Twaddle, S., Lowe, G.D., Clark, P., Greaves, M., Walker, I.D., Langhorne, P., Brenkel, I., Regan, L. and Greer, I. (2006) Screening for Thrombophilia in High-Risk Situations: Systematic Review and Cost-Effectiveness Analysis. The Thrombosis: Risk and Economic Assessment of Thrombophilia Screening (TREATS) Study. Health Technology Assessment, 10, 1-110. https:/doi.org/10.3310/hta10110 
[46] Vandenbroucke, J.P., Koster, T., Briet, E., Reitsma, P.H., Bertina, R.M. and Rosendaal, F.R. (1994) Increased Risk of Venous Thrombosis in Oral-Contraceptive Users Who Are Carriers of Factor V Leiden Mutation. Lancet, 344, 1453-1457.

https:/doi.org/10.1016/S0140-6736(94)90286-0

[47] Bezemer, I.D., Bare, L.A., Doggen, C.J., Arellano, A.R., Tong, C., Rowland, C.M., Catanese, J., Young, B.A., Reitsma, P.H., Devlin, J.J. and Rosendaal, F.R. (2008) Gene Variants Associated with Deep Vein Thrombosis. JAMA, 299, 1306-1314.

https:/doi.org/10.1001/jama.299.11.1306

[48] Rosendaal, F.R., Doggen, C.J., Zivelin, A., Arruda, V.R., Aiach, M., Siscovick, D.S., Hillarp, A., Watzke, H.H., Bernardi, F., Cumming, A.M., Preston, F.E. and Reitsma, P.H. (1998) Geographic Distribution of the 20210 G to A Prothrombin Variant. Thrombosis and Haemostasis, 79, 706-708.

[49] Poort, S.R., Rosendaal, F.R., Reitsma, P.H. and Bertina, R.M. (1996) A Common Genetic Variation in the 3'-Untranslated Region of the Prothrombin Gene Is Associated with Elevated Plasma Prothrombin Levels and an Increase in Venous Thrombosis. Blood, 88, 36983703.

[50] Rees, D.C., Cox, M. and Clegg, J.B. (1995) World Distribution of Factor V Leiden. Lancet, 346, 1133-1134. https:/doi.org/10.1016/S0140-6736(95)91803-5

[51] Lee, D.H., Henderson, P.A. and Blajchman, M.A. (1996) Prevalence of Factor V Leiden in a Canadian Blood Donor Population. CMAJ, 155, 285-289.

[52] Price, D.T. and Ridker, P.M. (1997) Factor V Leiden Mutation and the Risks for Thromboembolic Disease: A Clinical Perspective. Annals of Internal Medicine, 127, 895-903. https:/doi.org/10.7326/0003-4819-127-10-199711150-00007

[53] Rosendaal, F.R., Koster, T., Vandenbroucke, J.P. and Reitsma, P.H. (1995) High Risk of Thrombosis in Patients Homozygous for Factor V Leiden (Activated Protein C Resistance). Blood, 85, 1504-1508.

[54] Miletich, J., Sherman, L. and Broze Jr., G. (1987) Absence of Thrombosis in Subjects with Heterozygous Protein C Deficiency. New England Journal of Medicine, 317, 991-996. https:/doi.org/10.1056/NEJM198710153171604

[55] Tait, R.C., Walker, I.D., Reitsma, P.H., Islam, S.I., McCall, F., Poort, S.R., Conkie, J.A. and Bertina, R.M. (1995) Prevalence of Protein C Deficiency in the Healthy Population. Thrombosis and Haemostasis, 73, 87-93.

[56] Martinelli, I., Mannucci, P.M., De Stefano, V., Taioli, E., Rossi, V., Crosti, F., Paciaroni, K., Leone, G. and Faioni, E.M. (1998) Different Risks of Thrombosis in Four Coagulation Defects Associated with Inherited Thrombophilia: A Study of 150 Families. Blood, 92, 23532358.

[57] Koster, T., Rosendaal, F.R., Briët, E., van der Meer, F.J., Colly, L.P., Trienekens, P.H., Poort, S.R., Reitsma, P.H. and Vandenbroucke, J.P. (1995) Protein C Deficiency in a Controlled Series of Unselected Outpatients: An Infrequent but Clear Risk Factor for Venous Thrombosis (Leiden Thrombophilia Study). Blood, 85, 2756-2761.

[58] Di Minno, M.N., Ambrosino, P., Ageno, W., Rosendaal, F., Di Minno, G. and Dentali, F. (2015) Natural Anticoagulants Deficiency and the Risk of Venous Thromboembolism: A Meta-Analysis of Observational Studies. Thrombosis Research, 135, 923-932. https:/doi.org/10.1016/j.thromres.2015.03.010

[59] Dykes, A.C., Walker, I.D., McMahon, A.D., Islam, S.I. and Tait, R.C.A. (2001) Study of Protein S Antigen Levels in 3788 Healthy Volunteers: Influence of Age, Sex and Hormone Use, and Estimate for Prevalence of Deficiency State. British Journal of Haematology, 113, 636-641. https:/doi.org/10.1046/j.1365-2141.2001.02813.x

[60] Tait, R.C., Walker, I.D., Perry, D.J., Islam, S.I., Daly, M.E., McCall, F., Conkie, J.A. and Carrell, R.W. (1994) Prevalence of Antithrombin Deficiency in the Healthy Population. 
British Journal of Haematology, 87, 106-112.

https:/doi.org/10.1111/j.1365-2141.1994.tb04878.x

[61] Trussell, J. (2011) Contraceptive Failure in the United States. Contraception, 83, 397-404. https:/doi.org/10.1016/j.contraception.2011.01.021

[62] Van Vlijmen, E.F.W., Veeger, N.J.G.M., Middledorp, S., Hamulyak, K., Prins, M.H., Buller, H.R. and Meijer, K. (2011) Thrombotic Risk during Oral Contraceptive Use and Pregnancy in Women with Factor V Leiden or Prothrombin Mutation: A Rational Approach to Contraception. Blood, 188, 2055-2061. https:/doi.org/10.1182/blood-2011-03-345678

[63] Van Hylckama Vlieg, A., Helmerhorst, F. and Rosendaal, F. (2010) The Risk of Deep Venous Thrombosis Associated with Injectable Depot-Medroxyprogesterone Acetate Contraceptives or a Levonorgestrel Intrauterine Device. Arteriosclerosis Thrombosis and Vascular Biology, 30, 2297-2300. https:/doi.org/10.1161/ATVBAHA.110.211482

[64] Mantha, S., Karp, R., Raghavan, V., Terrin, N., Bauer, K.A. and Zwicker, J.I. (2012) Assessing the Risk of Venous Thromboembolic Events in Women Taking Progestin-Only Contraception: A Meta-Analysis. BMJ, 345, e4944. https:/doi.org/10.1136/bmj.e4944

[65] Lidegaard, O., Nielsen, L.H., Skovlund, C.W. and lokkegaard, E. (2012) Venous Thrombosis in Users of Non-Oral Hormonal Contraception: Follow up Study, Denmark 2001-10. BMJ, 344, e2990. https:/doi.org/10.1136/bmj.e2990

[66] Godfrey, E.M., Folger, S.G., Jeng, G., Jamieson, D.J. and Curtis, K.M. (2013) Treatment of Bleeding Irregularities in Women with Copper-Containing IUDs: A Systematic Review. Contraception, 87, 549-566. https:/doi.org/10.1016/j.contraception.2012.09.006

[67] Dore, D.D., Norman, H., Loughlin, J. and Seeger, J.D. (2010) Extended Case-Control Study Results on Thromboembolic Outcomes among Transdermal Contraceptive Users. Contraception, 81, 408-413. https:/doi.org/10.1016/j.contraception.2009.12.009

[68] Dinger, J., Mohner, S. and Heinemann, K. (2013) Cardiovascular Risk Associated with the Use of the Etonorgestrel-Containing Vaginal Ring. Obstetrics \& Gynecology, 122, 800-808. https:/doi.org/10.1097/AOG.0b013e3182a5ec6b

[69] Gerstman, B.B., Piper, J.M., Tomita, D.K., Ferguson, W.J., Stadel, B.V. and Lundin, F.E. (1991) Oral Contraceptive Estrogen Dose and the Risk of Deep Venous Thromboembolic Disease. American Journal of Epidemiology, 133, 32-37.

[70] Dinger, J.C., Heinemann, L.A.J. and Kuhl-Habich, D. (2007) The Safety of a DrospirenoneContaining Oral Contraceptive: Final Results from the European Active Surveillance Study on Oral Contraceptives Based on 142,475 Women-Years of Observation. Contraception, 75, 344-354. https:/doi.org/10.1016/j.contraception.2006.12.019

[71] Grimes, D.A. (2010) Epidemiologic Research Using Administrative Databases: Garbage in, Garbage out. Obstetrics \& Gynecology, 116, 1018-1019.

https:/doi.org/10.1097/AOG.0b013e3181f98300

[72] Dinger, J. and Shapiro, S. (2012) Interpreting Large but Incomplete Datasets. Journal of Family Planning and Reproductive Health Care, 38, 2-6. https:/doi.org/10.1136/jfprhc-2011-100260

[73] Heinemann, L.A.J., Dinger, J.C., Assmann, A. and Minh, T.D. (2010) Use of Oral Contraceptives Containing Gestodene and Risk of Venous Thromboembolism: Outlook 10 Years after the Third-Generation "Pill Scare". Contraception, 18, 401-407.

https:/doi.org/10.1016/j.contraception.2009.12.014

[74] Dinger, J., Assmann, A., Mohner, S. and Minh, T.D. (2010) Risk of Venous Thromboembolism and the Use of Dienogest- and Drospirenone-Containing Oral Contraceptives: Results from a German Case-Control Study. Journal of Family Planning and Reproductive Health Care, 36, 123-129. https:/doi.org/10.1783/147118910791749416

[75] Dinger, J., Bardenheuer, K. and Hienemann, K. (2014) Cardiovascular and General Safety 
of a 24-Day Regimen of Drospirenone-Containing Combined Oral Contraceptives: Final Results from the International Active Surveillance Study of Women Taking Oral Contraceptives. Contraception, 89, 253-263. https:/doi.org/10.1016/j.contraception.2014.01.023

[76] Reid, R.L. (2014) Oral Hormonal Contraception and Venous Thromboembolism (VTE). Contraception, 89, 235-236. https:/doi.org/10.1016/j.contraception.2014.02.002

[77] Bloemenkamp, K.W., Rosendaal, F.R., Helmerhorst, F.M. and Vandenbroucke, J.P. (2000) Higher Risk of Venous Thrombosis during Early Use of Oral Contraceptives in Women with Inherited Clotting Defects. Archives of Internal Medicine, 160, 49-52. https:/doi.org/10.1001/archinte.160.1.49

[78] Suissa, S., Spitzer, W.O., Rainville, B., Cusson, J., Lewis, M. and Heinemann, L. (2000) Recurrent Use of Newer Oral Contraceptives and the Risk of Venous Thromboembolism. Human Reproduction, 15, 817-821. https:/doi.org/10.1093/humrep/15.4.817

[79] Bergendal, A., Odlind, V., Persson, I. and Kieler, H. (2009) Limited Knowledge on Progestogen-Only Contraception and Risk of Venous Thromboembolism. Acta Obstetricia et Gynecologica, 88, 261-266. https:/doi.org/10.1080/00016340902730375

[80] World Health Organization Collaborative Study of cardiovascular Disease and Steroid Hormone Contraception (1998) Cardiovascular Disease and Use of Oral and Injectable Progestogen-Only Contraceptives and Combined Injectable Contraceptives: Results of an International, Multicenter, Case-Control Study. Contraception, 57, 315-324.

[81] Heinemann, L.A.J., Assmann, A., DoMinh, T. and Garbe, E. (1999) Oral Progestogen-Only Contraceptives and Cardiovascular Risk: Results from the Transnational Study on Oral Contraceptives and the Health of Young Women. European Journal of Contraception and Reproductive Health Care, 4, 67-73. https:/doi.org/10.3109/13625189909064007

\section{Submit or recommend next manuscript to SCIRP and we will provide best service for you:}

Accepting pre-submission inquiries through Email, Facebook, LinkedIn, Twitter, etc. A wide selection of journals (inclusive of 9 subjects, more than 200 journals)

Providing 24-hour high-quality service

User-friendly online submission system

Fair and swift peer-review system

Efficient typesetting and proofreading procedure

Display of the result of downloads and visits, as well as the number of cited articles

Maximum dissemination of your research work

Submit your manuscript at: http://papersubmission.scirp.org/

Or contact ojog@scirp.org 